\title{
ROTATOR MANŞET YIRTIKLARINDA MRG İLE KORAKOİD INKLINASYON AÇISI VE KORAKOAKROMİAL ARK AÇISININ DEĞERLENDÍRILMESI
}

\author{
Assesment of Coracoid Inclination Angle and Coracoacromial Arch Angle on MRI \\ in Rotator Cuff Tears
}

\author{
Neșe ASAL ${ }^{1}$
}

${ }^{I}$ Kırıkkale Üniversitesi Tıp Fakültesi, Radyoloji Anabilim Dalı, KIRIKKALE TÜRKIYYE

Amaç: $\mathrm{Bu}$ çalışmada, rotator manșet yırtıklarının etyolojisinde korakoid inklinasyon açısı ve korakoakromial ark açısının rolünün manyetik rezonans görüntüleme ile araştırılması amaçland1.

Gereç ve Yöntemler: Çalışmada Ocak 2014-Ocak 2019 tarihleri arası kliniğimizde çekilmiş total 102 omuz manyetik rezonans görüntüleme retrospektif olarak değerlendirildi. Supraspinatus tendonu, parsiyel yırtık ve tam kat yırtık açısından değerlendirildi. Tüm olgularda korakoid inklinasyon açıs1 ve korakoakromial ark açısı ölçümü yapıldı. Gruplar arasındaki karşılaştırmalar için independent t testi kullanıldı. Ayrıca korakoid inklinasyon açı ve korakoakromial ark açısı arasında Pearson korelasyon analizi yapıldı.

Bulgular: Rotator manşet yırtık olan grupta 29 kadın, 24 erkek olup yaş ortalaması $49.5 \pm 11.3$ yıl; kontrol grubunda 21 kadın, 28 erkek olup yaş ortalaması $45.08 \pm 11.7$ yıldı. Rotator manşet yırtık olan grupta; korakoid inklinasyon açı ortalaması $92.8 \pm 8^{\circ}$, korakoakromial ark açı ortalaması $127.4 \pm 7.3^{\circ}$ idi. Kontrol grubunda; korakoid inklinasyon açı ortalaması $106.5 \pm 9.5^{\circ}$, korakoakromial ark açı ortalaması $122.4 \pm 5^{\circ}$ idi. Gruplar arasında her iki açı değeri için istatistiksel anlamlı farklıl1k tespit edildi $(\mathrm{p}<0.05)$.

Sonuç: Rotator manşet yırtık olgularında, korakoid inklinasyon açısı daha dar ve korako-akromial ark açısı daha genişti. Korakoid proçes morfolojisi ve buna bağlı değişken korakoid inklinasyon açısı, korakoakromial ark aç1sı rotator manşet yırtıkları için predispozan faktörler olabilir, rotator manşet patolojilerinin etyolojisini belirlemede yardımcı olarak kullanılabilir.

Anahtar Kelimeler: Korakoid, impingement sendromu, manyetik rezonans görüntüleme, rotator manşet
Objective: The purpose of this study was to investigate the role of the coracoid inclination angle and the coracoacromial arch angle in the etiology of rotator cuff tears on magnetic resonance imaging.

Material and Methods: A total of 102 shoulder magnetic resonance imaging taken in our clinic between January 2014 and January 2019 were retrospectively evaluated. Supraspinatus tendon was evaluated for partial tear and full tear. The coracoid inclination angle and the coracoacromial arch angle were measured in all cases. Independent $t$ test was used for comparisons between groups. Pearson correlation analysis was performed between the coracoid inclination angle and the coracoacromial arch angle.

Results: There were 29 female and 24 male patients in the rotator cuff tear group and the mean age was $49.5 \pm 11.3$ years. There were 21 female and 28 male patients in the control group and the mean age was $45.08 \pm 11.7$ years. In the rotator cuff tear group; the mean coracoid inclination angle was $92.8 \pm 8^{\circ}$ and the mean coracoacromial arch angle was $127.4 \pm 7.3^{\circ}$. In the control group; the mean coracoid inclination angle was $106.5 \pm 9.5^{\circ}$ and the mean coracoacromial arch angle was $122.4 \pm 5^{\circ}$. A statistically significant difference was found between the groups for both angle values $(\mathrm{p}<0.05)$.

Conclusion: The coracoid inclination angle was narrower and the coracoacromial arch angle was wider in rotator cuff tear cases. Coracoid process morphology and related variable coracoid inclination angle, coracoacromial arch angle may be the predisposing factors for rotator cuff tears and may be used to help determine the etiology of rotator cuff pathologies.

Keywords: Coracoid, impingement syndrome, magnetic resonance imaging, rotator cuff 


\section{GíRiș}

İmpingement sendromu omuz ağrısının yaşla artan en s1k nedeni olup rotator manşet patolojilerinin \%70 ile ilişkilidir (1-3). Rotator manşet yırtklarının (RMY) etyolojisi multifaktoriyeldir. $\mathrm{Bu}$ faktörler intirinsik, ekstrinsik ve travmatik olabilmektedir (3). Literatürde rotator manşet patolojilerinin nedenlerini araştıran çok sayıda çalışma mevcuttur (4). Çalışmalarda akromion şekli, lateral akromion açısı, akromial kapsama alanı, skapular hareket, korakoakromial ligament, akromioklavikuler ligament RMY ile ilişkilendirilen predispozan faktörler olarak rapor edilmiştir $(2,4)$. Ancak korakoid proçes şekline bağlı korakoakromial ligament değişkenliklerinin ve buna sekonder subakromial mesafedeki değişkenliklerin araştırıldığı az sayıda çalışma mevcuttur (4). Korakoakromial ark, akromion, korakoakromial ligament ve korakoid proçesi kapsar. Korakoid proçes morfolojik varyasyonları, korakoakromial ark ve rotator manşet arasındaki alanın boyut ve şeklinde değişkenliklere neden olmaktadır (5).

$\mathrm{Bu}$ çalışmada, rotator manşet yırtıklarının etyolojisinde korakoid inklinasyon açısı ve korakoakromial ark açısının rolünün manyetik rezonans görüntüleme (MRG) ile tespiti amaçlandı.

\section{MATERYAL VE METOD}

\section{Çalışma Popülasyonu}

Çalışmada, Ocak 2014-Ocak 2019 tarihleri arasında 18 yaş üzeri olgulara kliniğimizde çekilmiş 704 omuz MRG retrospektif olarak tarand1. Rotator manşette supraspinatus tendonunda yırtık olan ve tip 1 akromion mevcut 53 hasta grubu ve RMY olmayan, tip 1 akromion mevcut, yaş ve cinsiyet açısından hasta grubu ile uyumlu 49 kontrol grubuna ait total 102 omuz MRG çalışmaya dahil edildi. Çalışmaya dahil edilen olguların omuz ağrısı, impingement sendromu, hareket kısıtlılığı gibi ortopedik muayene bulguları mevcuttu.
Çalışmada, her iki gruptan travma, tümör, omuz cerrahisi, osteoartrit gibi omuz eklemlerini tutan dejeneratif hastalıklar, inflamatuar eklem hastalığı gibi ölçümlerde değişikliklere neden olabilecek klinik durumlara sahip olgular çıkarıldı. Ayrıca ölçümlerde etkili faktör olabilecek akromion tip 2, 3, 4 ve rotator manşette anterior impingement sendromunu dışlamak amaçlı subskapularis tendonunda yırtık olanlar da çalışma dışı bırakıldı. Etik kurul onayı Kırıkkale Üniversitesi Girişimsel olmayan Etik Kurulu tarafından alındı ve çalışma Helsinki Deklarasyonu'na uygun olarak hazırlandı (Tarih: 06.02.2019; Karar No:19/032019.02.08).

MRG Inceleme ve Ölçümler

MRG yüzey omuz koili kullanılarak 1.5 Tesla MR cihazı (Philips MRG Sistemleri, Achieva Release 3.2 Seviye 2013-10-21, Philips Medical Systems Nederland B.V) ile yapıldı. İncelemede T1 ağırlıklı; T1-TSE (Turbo Spin-Echo) aksiyal, T1-TSE oblik koronal (780/15; FOV 14 cm; kesit kalınlığı 3.5 mm; cross-sectional $0.4 \mathrm{~mm}$; matriks $320 \times 256$ ), T2 ağırlıklı; T2-FFE (Fast-Field Echo) aksiyal, T2-TSE oblik sagittal, T2 ağırlıklı yağ baskılanmış, T2-SPAIR (spectral attenuated inversion recovery) aksiyal ve oblik koronal (3400/50; FOV, 14 cm; kesit kalınlığı 3.5 $\mathrm{cm}$; cross-sectional $0.4 \mathrm{~mm}$, matriks, $256 \times 256$ ) görüntüler elde edildi. Tüm MRG incelemeleri standart omuz protokolüne göre ve özel pozisyonlama tekniği kullanılmadan gerçekleştirildi.

MRG'de supraspinatus tendonu, parsiyel yırtık ve tam kat yırtık açısından değerlendirildi. Korakoid inklinasyon açısı; aksiyal T2-FFE sekansta, korakoid ucu anterior korteksi boyunca uzanan hat ile glenoid yüzeyine anteriordan posteriora doğru teğet çizilen hat arasındaki açı ölçüldü (4) (Şekil 1,3). Korakoakromial ark açıs1; oblik sagittal T2-TSE sekansta, akromion uzun aksına teget çizilen hat ile korakoakromial ligament aksına çizilen hat arasındaki açı ölçüldü (2) (Şekil 2,4). 
Asal N.

Tüm MRG'lerin değerlendirmesi ve ölçümler kas iskelet radyolojisinde tecrübeli tek radyolog tarafindan 4 hafta ara ile 2 kez gerçekleştirildi (N.A).

\section{Istatistiksel Analiz}

Veri analizi SPSS 20.0 istatistik paket programı (Statistical Package for the Social Sciences, version 20.0, SPPSS Inc, Chicago, IL, USA) kullanılarak yapıldı. Sürekli değişkenlerin normal dağılımı Kolmogorov Smirnov testi ile analiz edildi. Değişkenler, aritmetik ortalama \pm standart sapma (SS) olarak ifade edildi. Gruplar arası cinsiyet gibi kategorik değişkenler ki kare testi kullanılarak karşılaştırıldı ve ortalamalar ve yüzdelikler hesaplandı. Grupların karşılaştırılması için independent $\mathrm{t}$ testi kullanıldı. $\mathrm{P}<0.05$ anlamlı olarak kabul edildi. Korakoid inklinasyon açısı ve korakoakromial ark açısı arasında Pearson korelasyon analizi yapıldı. Korelasyon katsayısı 0.00-0.25 arasında çok zayıf ilişki, 0.25-0.49 arasında zayıf ilişki, 0.50-0.69 arasında orta ilişki, 0.70-0.89 arasında yüksek ilişki, 0.90-1.0 arasında çok yüksek ilişki var olarak değerlendirildi. Gözlemcinin kendi içinde uyumu Kappa testi kullanılarak değerlendirildi ve yorumland1.

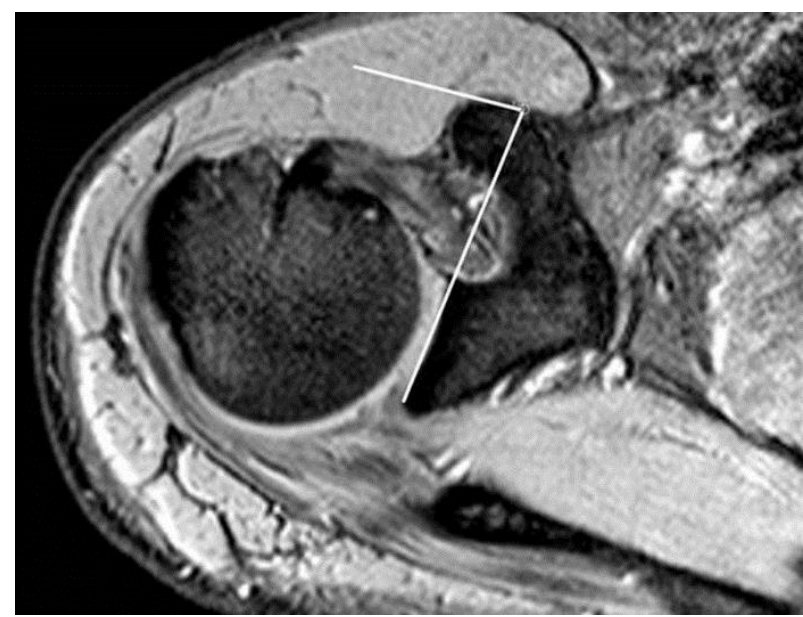

Şekil 1: Aksiyal T2-FFE sekansta, rotator manşet yırtığı mevcut 36 yaş erkek olgu, korakoid inklinasyon açısı ölçümü

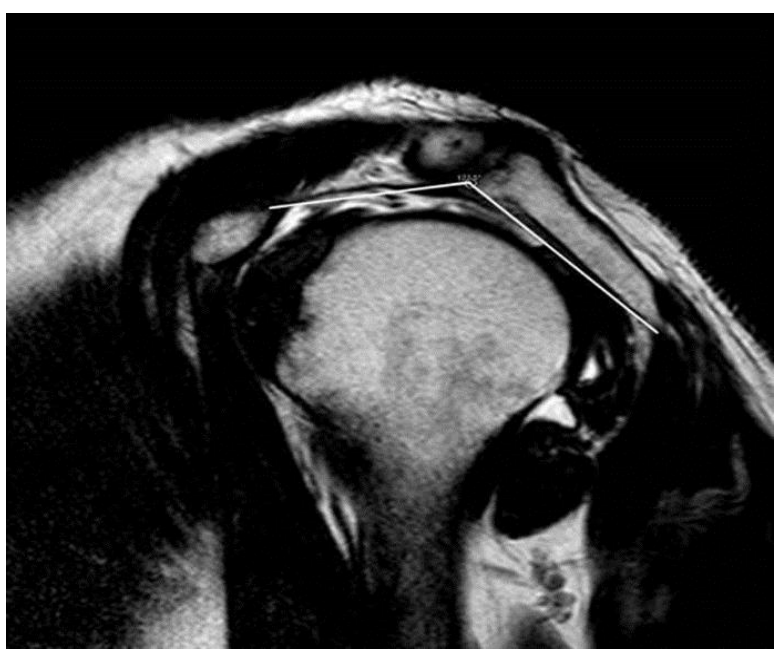

Şekil 2: Oblik sagittal T2-TSE sekansta, rotator manşet yırtığ1 mevcut 66 yaş kadın olgu, korako-akromial açı ölçümü

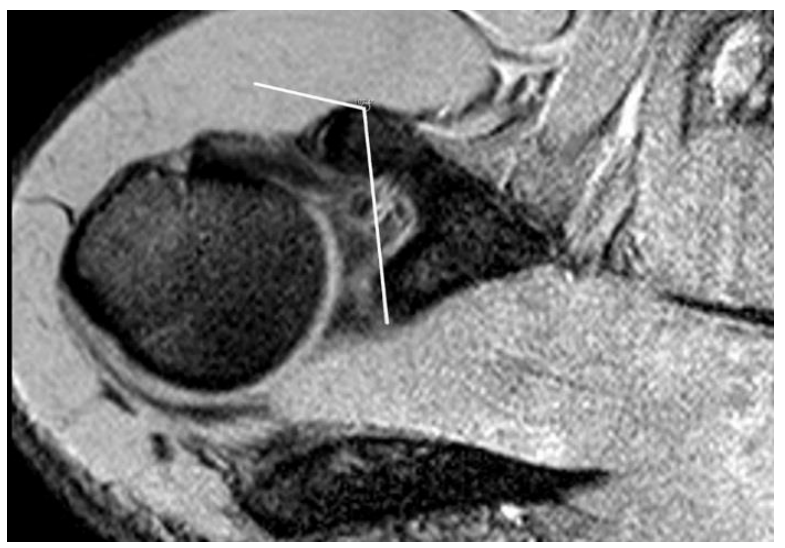

Şekil 3: Aksiyal T2-FFE sekansta, kontrol grubu 28 yaş kadın olgu, korakoid inklinasyon açısı ölçümü

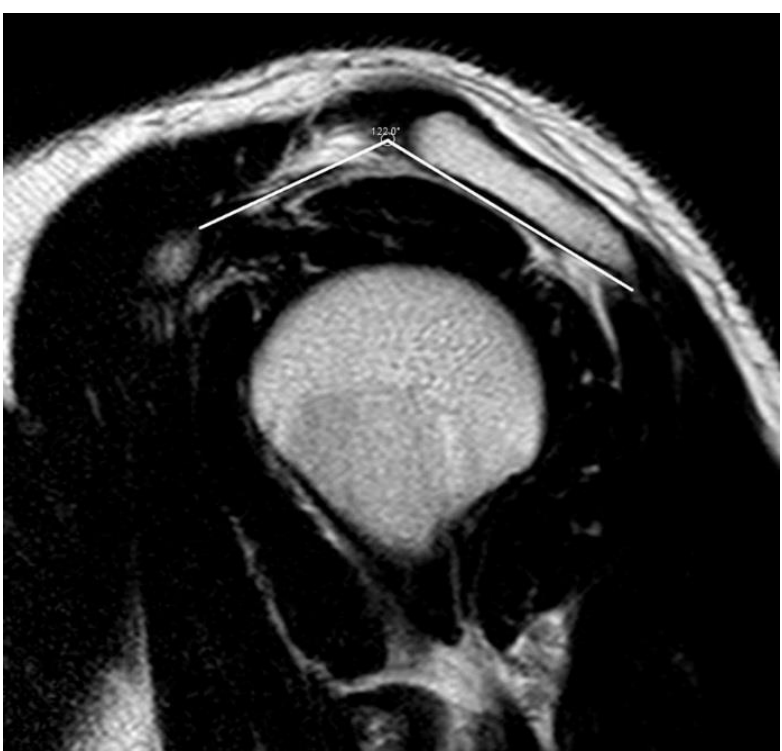

Şekil 4: Oblik sagittal T2-TSE sekansta, kontrol grubu 35 yaş kadın olgu, korako-akromial açı ölçümü 


\section{BULGULAR}

RMY olan grupta 53 olgunun 29 (\%54.7)'u kadın, 24 (\%45.3)'ü erkek ve yaş ortalaması $49.45 \pm 11.3$ yıldı. RMY olmayan kontrol grupta 49 olgunun 21 (\%42.9)'u kadın, 28 (\%57.1)'i erkek ve yaş ortalaması $45.08 \pm 11.7$ yıldı. Gruplar arasında yaş ve cinsiyet açısından farklılık izlenmedi. RMY grubunda olguların 18 (\%34)'ünde supraspinatus tendonunda tam kat yırtık, 35 (\%66)'sında parsiyel yırtık saptand1. RMY olan grupta; korakoid inklinasyon açı ortalaması $92.8 \pm 8^{\circ}$, korakoakromial ark açı ortalaması $127.4 \pm 7.3^{\circ}$ idi. Kontrol grubunda; korakoid inklinasyon açı ortalaması $106.5 \pm 9.5^{\circ}$, korakoakromial ark açı ortalaması $122.4 \pm 5^{\circ}$ idi. Gruplar arasında her iki açı değeri için anlamlı farklılık tespit edildi $(\mathrm{p}<0.05)$. Ayrıca korakoid inklinasyon açısı ile korakoakromial ark açısı arasında çok zayıf negatif ilişki izlendi ( $\mathrm{r}=-0.194, \mathrm{p}=0.049)$. Korakoid inklinasyon açı ve korakoakromial ark açısı için kappa değerleri, gözlemci içi değerlendirmede 1lımlı uyum gösterdi (sırayla 0.512;0.485).

\section{TARTIŞMA}

$\mathrm{Bu}$ çalışmanın temel bulgusu RMY mevcut hastalarda, kontrol grubu olgularına göre korakoid inklinasyon açısı daha dar ve korakoakromial ark açısı daha genişti. RMY'nin patogenezi hala net değildir. Neer ve ark. kronik impingement sendromunda ekstrinsik faktörleri öne sürerken, Codman ve Akerson rotator manşet patolojilerinde intrinsik nedenleri açıklamıştır $(6,7)$. Literatürde önceki çalışmalarda, öne eğimi artmış akromion tipi RMY ile yüksek oranda ilişkilendirilmiştir (8-11). Bu çalışmada rotator manşet patolojilerindeki etkisini dışlamak amaçlı akromion 2, 3 ve 4 çalışmadan çıkarıldı. Korakoid proçes, korakohumeral mesafeyi daraltması nedeniyle subkorakoid impingement açısından önemli bir faktör olarak tartışılmıştır (5,12-14). Korakoid proçes morfolojisi korakoakromial ligament aksında değişikliğe neden olarak akromionun öne eğimini artırır ve subakromial mesafeyi de daraltabilmektedir (4-15). Dahası korakoakromial ligamentin oluşturduğu biyomekanik strese bağlı ilerleyen süreçte akromion ucunda osteofit oluşumu artmaktadır (11).

$\mathrm{Bu}$ çalışmada, korakoid proçesteki morfolojik değişikliklere sekonder anterior sıkışma sendromu hariç tutularak korakoidin diğer RMY'deki etkisi korakoid inklinasyon açı ölçümü ile araştırıldı. Dahası çalışmamızda korakoakromial ark açı ölçümü de dahil edildi ve korakoid inklinasyon açısı ile korakoakromial ark açısı arasındaki ilişkide analiz edildi. Çalışmanın, primer amacı korakoid inklinasyon açısı ve korakoakromial ark açısının RMY için predispozan faktörler olup olmadığını analiz etmekti.

Kesmezaçar ve ark. korakoakromial ligaman anatomik varyantları ve farklı korakoid proçes tutunma paternlerini araştırdıkları anatomik kadavra çalışmalarında, büyük korakoid insersiyo ve birden fazla band içeren korakoakromial ligamanın rotator manşet dejenerasyonunda etkili olduğunu rapor etmişlerdir (16). Kanatlı ve ark. parsiyel RMY ile korakoakromial ligament dejenerasyonu ilişkisini araştırdıkları çalışmalarında, korakoakromial ligament dejenerasyonunu impingement sendromunda etkili faktör olarak bildirmişlerdir (17).

Torrens ve ark. RMY olgularında bilgisayarlı tomografi (BT) üzerinde farklı 3 yöntem ile korakoid inklinasyon açısında azalma tespit etmişlerdir (4). Çalışmamızda, korakoid inklinasyon açı ortalama değerleri RMY olan grupta; $92.8 \pm 8^{\circ}$, kontrol grubunda; $106.5 \pm 9.5^{\circ}$ idi. RMY olan olgularda, korakoid inklinasyon açısı dardı ve gruplar arasında anlamlı farklılık tespit edildi. Bu çalışmada her iki grup korakoid inklinasyon açı değerleri Torrens ve ark.'nın çalışmasına göre daha yüksekti. Onlar çalışmalarında spesifik pozisyonlama kullanımı bildirmemişlerdir (4). Çalışmamızda da standart pozisyonlama kullanılmıştır. $\mathrm{Bu}$ farklılığın kol hareketine bağlı olmadığı düşünüldü. $\mathrm{Bu}$ çalışma MRG ile gerçekleştirilmiştir. Yumuşak doku rezolüsyonu ve multiplanar görüntüleme 
özellikleri nedeniyle MRG patolojilerin tanısında önemli görüntüleme yöntemidir (2,18). Ancak kemik yapıları görüntülemede BT, MRG'ye göre daha üstün ve daha optimize değerler sunar (18). Aç1 değerlerindeki farklılığın bu incelemenin MRG ile yapılmış olmasına bağlı olabileceği düşünülmüştür. Literatürde yapılan biyomekanik çalışmalara göre, omuz hareketine bağlı korakoakromial ligament ve rotator manşet tendonları arasında temas gözlenmiştir (19). Ayrıca Brunkhorst ve ark. dinamik kol hareketine bağlı korakohumeral mesafedeki değişkenlikleri araştırdıkları çalışmalarında, omuzun internal rotasyonuna bağlı korakohumeral mesafede daralma rapor etmişlerdir (20). Omuz hareketleri anatomik yapılarda ve mesafelerde değişkenlikler yapabilir ve dinamik MRG incelemeler verileri destekleyici olabilir.

Çay ve ark. RMY'da korakoakromial ark açısını değerlendirdikleri çalışmalarında korakoakromial açı değerlerini RMY olan grupta; 132.38 , kontrol grubunda; $116.95^{\circ}$ saptamışlardır (2). Onlar hasta grubunda kontrol grubuna göre daha yüksek aç1 değerleri tespit etmiş ve korakoakromial ark açısının rotator manşet patolojileri için predispozan faktör olabileceğini sunmuşlardır (2). Çalışmamızda, korakoakromial ark açı ortalama değerleri RMY olan grupta; $127.4 \pm 7.3^{\circ}$, kontrol grubunda; $122.4 \pm 5^{\circ}$ idi. Çay ve ark.'nın çalışmasına benzer şekilde, RMY olan olgularda, korakoakromial ark açı değerleri yüksekti ve gruplar arası istatistiksel olarak anlamlı farklılık tespit edildi (2). Dahası, bu çalışmada korakoid inklinasyon açısı ve korakoakromial ark açısı arasında çok zayıf negatif ilişki mevcuttu. Korakoid inklinasyon açısında azalmaya bağlı korakoakromial ligamentin daha dik hale gelmesine sekonder geniş korakoakromial ark açı değerlerine neden olduğu düşünülmüştür.

Çalışmanın bazı limitasyonları mevcuttu. Birincisi, çalışmanın retrospektif naturde olması ve spesifik pozisyonlama yapılamamasıdır. İkincisi, verilerin BT ve artroskopi bulguları ile korele edilememesidir. Üçüncüsü, tüm ölçümlerin tek radyolog tarafindan değerlendirilmesi ve gözlemciler arası farklılığın sunulamamasıdır. Ancak tüm bunlara rağmen bu çalışma anlamlı veriler sundu. Daha büyük vakakontrol grubunu içeren, artroskopik bulgular ile korele edilen ve farklı ölçüm metodlarının dahil edildiği destekleyici çalışmalara ihtiyaç vardır.

RMY olgularında, korakoid inklinasyon açısı düşüktü ve korakoakromial ark açı değerleri yüksekti. Açı değerleri arasında negatif korelasyon vardı. Korakoid proçes morfolojisi ve buna bağlı azalmış korakoid inklinasyon açısı, artmış korakoakromial ark açısı RMY için predispozan faktörler olup rotator manşet patolojilerinin etyolojisini belirlemeye yardımcı olarak kullanılabilir.

Çıkar Çatışması Beyanı: Herhangi bir çıkar çatışması yoktur.

\section{KAYNAKLAR}

1. Bodo K, Abbas M, Temperley D, Midgley A, Monga P. A Novel MRI Measurement for Analysing Coracoacromial Morphology. Int $\mathrm{J}$ Orthopaedics. 2018;5(1):883-890.

2. Cay N, Tosun O, Isik C, Unal O, Kartal MG, Bozkurt M. Is coracoacromial arch angle a predisposing factor for rotator cuff tears? Diagn Interv Radiol. 2014;20(6):498-502.

3. Balke M, Liem D, Greshake O, Hoeher J, Bouillon B, Banerjee M. Differences in acromial morphology of shoulders in patients with degenerative and traumatic supraspinatus tendon tears. Knee Surgery, Sports Traumatology, Arthroscopy. 2016;24(7):2200-5.

4. Torrens C, Alentorn-Geli E, Sanchez JF, Isart A, Santana F. Decreased axial coracoid inclination angle is associated with rotator cuff tears. J Orthop Surg (Hong Kong).2017;25(1):2309499017690329. 
5. Okoro T, Reddy V, Pimpelnarkar A. Coracoid impingement syndrome: a literature review. Curr Rev Musculoskelet Med. 2009;2(1):51-5.

6. Neer CS 2nd. Anterior acromioplasty for the chronic impingement syndrome in the shoulder. 1972. J Bone Joint Surg Am. 2005;87(6):1399.

7. Codman EA, Akerson IB. The pathology associated with rupture of the supraspinatus tendon. Ann Surg. 1931;93(1):348-59.

8. Balke M, Liem D, Greshake O, Hoeher J, Bouillon B, Banerjee M. Differences in acromial morphology of shoulders in patients with degenerative and traumatic supraspinatus tendon tears. Knee Surg Sports Traumatol Arthrosc. 2016;24(7):2200-5.

9. Bigliani L, Morrison D, April E. The morphology of the acromion and rotator cuff impingement. Orthop Trans. 1986;10:228.

10. Edelson J, Taitz C. Anatomy of the coraco-acromial arch. Relation to degeneration of the acromion. J Bone Joint Surg British volume. 1992;74(4):58994.

11. Sakoma Y, Sano H, Shinozaki N, Itoigawa Y, Yamamoto N, Itoi E. Coverage of the humeral head by the coracoacromial arch: relationship with rotator cuff tears. Acta Medica Okayama. 2013;67(6):377-83.

12. Cetinkaya M, Ataoglu MB, Ozer M, Ayanoglu T, Kanatli U. Subscapularis tendon slip number and coracoid overlap are more related parameters for subcoracoid impingement in subscapularis tears: a magnetic resonance imaging comparison study. Arthroscopy. 2017;33(4):734-42.

13. Dugarte AJ, Davis RJ, Lynch TS, Schickendantz MS, Farrow LD. Anatomic Study of Subcoracoid Morphology in 418 Shoulders: Potential Implications for Subcoracoid Impingement. Orthop J Sports Med. 2017;5(10):2325967117731996.
14. Osti L, Soldati F, Del Buono A, Massari L. Subcoracoid impingement and subscapularis tendon: is there any truth? Muscles Ligaments Tendons J. 2013;3(2):101.

15. McBain L, Simonds E, Iwanaga J, Tubbs RS. Review of the pathology and congenital anomalies of the coracoid process with clinical applications. Translational Research in Anatomy. 2018;10:4-6.

16. Kesmezacar H, Akgun I, Ogut T, Gokay S, Uzun I. The coracoacromial ligament: the morphology and relation to rotator cuff pathology. J Shoulder Elbow Surg. 2008;17(1):182-8.

17. Kanatli U, Ayanoglu T, Aktas E, Ataoglu MB, Ozer M, Cetinkaya M. Grade of coracoacromial ligament degeneration as a predictive factor for impingement syndrome and type of partial rotator cuff tear. J Shoulder Elbow Surg. 2016;25(11):1824-8.

18. Watson AC, Jamieson RP, Mattin AC, Page RS. Magnetic resonance imaging based coracoid morphology and its associations with subscapularis tears: a new index. Shoulder Elbow. 2019;11(1 Suppl):52-58. Doi:10.1177/1758573217744170. (Epub 2017 Dec 11).

19. Yamamoto N, Muraki T, Sperling JW, Steinmann SP, Itoi E, Cofield RH et al. Contact between the coracoacromial arch and the rotator cuff tendons in nonpathologic situations: a cadaveric study. J Shoulder Elbow Surg. 2010;19(5):681-7.

20. Brunkhorst JP, Giphart JE, LaPrade RF, Millett PJ. Coracohumeral distances and correlation to arm rotation: an in vivo 3-dimensional biplane fluoroscopy study. Orthop J Sports Med. 2013;1(2):2325967113496059. 